Supporting Information

\title{
Fluorescent Covalently Crosslinked Cellulose Networks via Light-Induced Ligation
}

\author{
Andrea Hufendiek, ${ }^{a, b, c}$ Anna Carlmark, ${ }^{d}$ Michael A. R. Meier*a and \\ Christopher Barner-Kowollik $* b, c$
}

${ }^{a}$ Laboratory of Applied Chemistry, Institute of Organic Chemistry (IOC), Karlsruhe Institute of Technology (KIT), Fritz-Haber-Weg 6, 76131 Karlsruhe, Germany. E-mail: m.a.r.meier@kit.edu.

${ }^{b}$ Preparative Macromolecular Chemistry, Institut für Technische Chemie und Polymerchemie, Karlsruhe Institute of Technology (KIT), Engesserstr. 18, 76128 Karlsruhe, Germany. Fax: +49 721608 45740; E-mail: christopher.barner-kowollik@kit.edu.

${ }^{c}$ Institut für Biologische Grenzflächen, Karlsruhe Institute of Technology (KIT), Herrmann-vonHelmholtz-Platz 1, 76344 Eggenstein-Leopoldshafen, Germany.

${ }^{d}$ KTH Royal Institute of Technology, Department of Fibre and Polymer Technology, Teknikringen 56, SE-100 44 Stockholm, Sweden. 


\section{Materials}

Acetic acid (Roth, 100\%), acetic anhydride (Acros, > 99\%,) p-Anisidine (ABCR, 99\%), $N$ (dimethylaminopropyl)- $N$ '-ethylcarbodiimide hydrochloride $\quad$ (EDC; Roth, 99\%), 4(dimethylamino)pyridine (DMAP; Sigma Aldrich, 99\%), dimethyl carbonate (Acros, 99\%), $N, N$ dimethylformamide (DMF; VWR Analpur), dimethyl sulfoxide (DMSO; Carl Roth, 99.8\%), furan (Acros, 99\%), 3,3'-dithiopropionic acid(Aldrich, 99\%), 4-formylbenzoic acid (TCI, 98\%), hydrochloric acid (Roth, 37\%), maleic anhydride (Alfa Aesar, 98\%), potassium carbonate (technical), pyridine (Sigma Aldrich, 99.8\%), sodium acetate (Roth, 99\%), sodium nitrite (Alfa Aesar, 98\%), DL-dithiothreitol (DTT; AppliChem, $\geq 99.5 \%$ ) $p$ - toluenesulfonyl hydrazide (Alfa Aesar, 98\%), 1,5,7-triazabicyclo[4.4.0]dec-5-ene (TBD; Sigma Aldrich, 98\%), of 4,7,10-trioxa1,13-tridecanediamine (Sigma Aldrich, 97\%) and triethylamine (Merck, 99\%) were used as received. All other solvents were of analytical grade and used as received. 1-Butyl-3methylimidazolium chloride (BMIMCl; Aldrich, 95\%), lithium chloride (Sigma Aldrich, 99\%), and Whatman filter paper no. 5 were stored in a desiccator over silica gel. Ethanolamine (Acros, 99\%) was dried over molecular sieve (3 $\AA$ ) prior to use.

\section{Characterization Methods}

NMR measurements were performed on a Bruker Ascend spectrometer operating at $400 \mathrm{MHz}$ for ${ }^{1} \mathrm{H}$ nuclei and $100 \mathrm{MHz}$ for ${ }^{13} \mathrm{C}$ nuclei, respectively. All NMR spectra were recorded at ambient temperature. The chemical shifts $\delta$ were referenced to the solvent residual signals, respectively $\left(\delta_{\mathrm{H}}\left(\mathrm{CHCl}_{3}\right)=7.26, \delta_{\mathrm{H}}(\mathrm{DMSO})=2.50, \delta_{\mathrm{C}}(\mathrm{DMSO})=39.52\right) . J$ values are given in $\mathrm{Hz}$. The degree of substitution (DS) of cellulose 4-(2-(4-methoxyphenyl)-2H-tetrazol-5-yl) benzoate (cellulose-tetrazole) was determined according to a procedure adopted from the literature. ${ }^{1,2} \mathrm{~A}$ defined amount of maleic acid as the standard and a defined amount of the cellulose-tetrazole 
were dissolved in DMSO- $d_{6}$. The $D S$ was calculated using the integral ratio of the ${ }^{1} \mathrm{H}$ NMR resonance corresponding to the aromatic protons $\mathbf{d}, \mathbf{e}, \mathbf{i}, \mathbf{j}$ of the cellulose-tetrazole (Figure S1) and the resonance corresponding to the double bond protons of the maleic acid $(\delta=6.27 \mathrm{ppm})$.

Size exclusion chromatography (SEC). SEC on the cellulose-tetrazoles and the cellulose networks after reductive degradation was performed at a sample concentration of $1-2 \mathrm{~g} \mathrm{~L}^{-1}$ with DMAc containing $10 \mathrm{~g} \mathrm{~L}^{-1} \mathrm{LiCl}$ as eluent at $70{ }^{\circ} \mathrm{C}$ on an Agilent Series $1200 \mathrm{HPLC}$ system including an isocratic pump (G1310A), an autosampler (G1329A), a thermostat controlled column compartment $(\mathrm{G} 1316 \mathrm{~A})$, a refractive index detector $(\mathrm{G} 1362 \mathrm{~A})$ that was kept at $50{ }^{\circ} \mathrm{C}$, and a diode array and a multiple wavelength detector (G1315D) at a flow rate of $0.5 \mathrm{~mL} \mathrm{~min}^{-1}$. The separation was achieved on a SEC column (PSS, GRAM analytical, $300 \times 8.00 \mathrm{~mm}, 10 \mu \mathrm{m}$ particle size, $3000 \AA$ porosity $)$ with a precolumn $(50 \times 8.00 \mathrm{~mm})$. Linear poly $($ methyl methacrylate) standards with molecular weights ranging from 4300 to $3.73 \times 10^{6} \mathrm{~g} \mathrm{~mol}^{-1}$ were used for calibration. The samples were filtered through PTFE membranes with a pore size of $0.45 \mu \mathrm{m}$ prior to injection. Dissolution of Whatman filter paper no. 5 was achieved in a solvent exchange procedure adopted from the literature..$^{3-5}$

UV-vis measurements. UV-vis spectra were recorded on a Cary 300 Bio UV-vis spectrophotometer (Varian) at ambient temperature in DMSO from $200 \mathrm{~nm}$ to $800 \mathrm{~nm}$ with a resolution of $1 \mathrm{~nm}$ and a slit width of $2 \mathrm{~nm}$.

Fluorescence measurements. Fluorescence emission spectra were recorded on a Varian Cary Eclipse spectrometer at an excitation wavelength of $365 \mathrm{~nm}$. Samples of thin films were placed in a quartz cuvette of $2 \mathrm{~mm}$ thickness, which was placed in the sample holder in a $45^{\circ}$ angle. The spectra were recorded from $400 \mathrm{~nm}$ to $800 \mathrm{~nm}$ at an excitation slit width of $5 \mathrm{~nm}$, an emission slit 
width of $5 \mathrm{~nm}$, a resolution of $0.5 \mathrm{~nm}$, and a scan rate of $30 \mathrm{~nm} \mathrm{~min}^{-1}$. A filter was applied from 430-1100 $\mathrm{nm}$. The reference sample was prepared in the same manner as network 1 and network 2 employing cellulose-tetrazole 2 without the addition of a bismaleimide linker. The reference sample was whashed extensively with methanol and subsequently dried with a stream of compressed air.

Photoluminescence Quantum Yield (PLQY). PLQY was determined for solutions in $\mathrm{LiCl} / \mathrm{DMAc}\left(10 \mathrm{~g} \mathrm{~L}^{-1}\right)$ obtained from network 2 and network 4 after the reduction of disulfide bonds (see below) on a Hamamatsu Quantaurus QY at an excitation wavelength of $\lambda_{\mathrm{ex}}=400 \mathrm{~nm}$ in the emission range in wavelengths from $450-800 \mathrm{~nm}$.

Differential scanning calorimetry (DSC). DSC experiments were carried out on a DSC821e (Mettler Toledo) calorimeter, under nitrogen atmosphere, at a heating rate of $10 \mathrm{~K} \mathrm{~min}^{-1}$ from $25^{\circ} \mathrm{C}$ up to a temperature of $350^{\circ} \mathrm{C}$, and using a sample mass of approximately $5 \mathrm{mg}$. Prior to data acquisition the samples were heated at a heating rate of $10{ }^{\circ} \mathrm{C} \min ^{-1}$ to $125^{\circ} \mathrm{C}$ and kept at this temperature for $10 \mathrm{~min}$ to remove water and solvent residues, and subsequently cooled to $25^{\circ} \mathrm{C}$ at a cooling rate of $-20^{\circ} \mathrm{C} \min ^{-1}$.

Thermogravimetric Analysis (TGA). TGA was perfomed on a Du Pont Instruments 951 Thermogravimetric Analyzer in a nitrogen atmosphere (nitrogen flow: $100 \mathrm{~mL} \mathrm{~min}{ }^{-1}$ ). The samples were heated to $125{ }^{\circ} \mathrm{C}$ at a heating rate of $10 \mathrm{~K} \mathrm{~min}^{-1}$ and kept at $125{ }^{\circ} \mathrm{C}$ for $20 \mathrm{~min}$. Subsequently, the samples were heated to $730{ }^{\circ} \mathrm{C}$ at a heating rate of $10 \mathrm{~K} \mathrm{~min}^{-1}$. 


\section{Experimental Procedures}
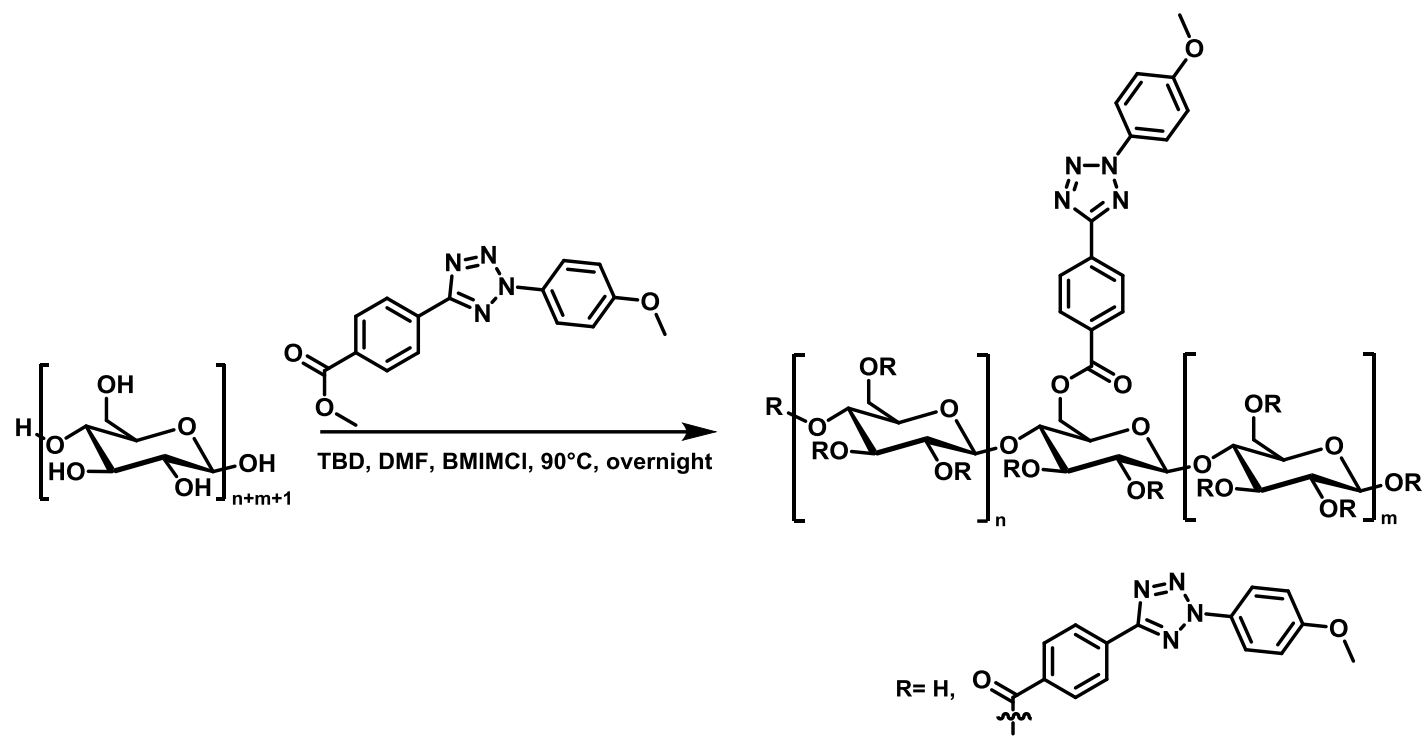

Scheme S1: Synthesis of cellulose 4-(2-(4-methoxyphenyl)-2H-tetrazol-5-yl) benzoate (cellulose-tetrazole).

\section{Cellulose 4-(2-(4-methoxyphenyl)-2H-tetrazol-5-yl) benzoate (cellulose-tetrazole)}

Cellulose-tetrazole was synthesized from Whatman filter paper no. 5 in solution in BMIMCl/DMF following a previous report employing a transesterification procedure with an isolated product yield of $75 \%{ }^{2,} 6$ The experimental conditions for the synthesis of cellulosetetrazole 1-3 are summarized in Table 1. 


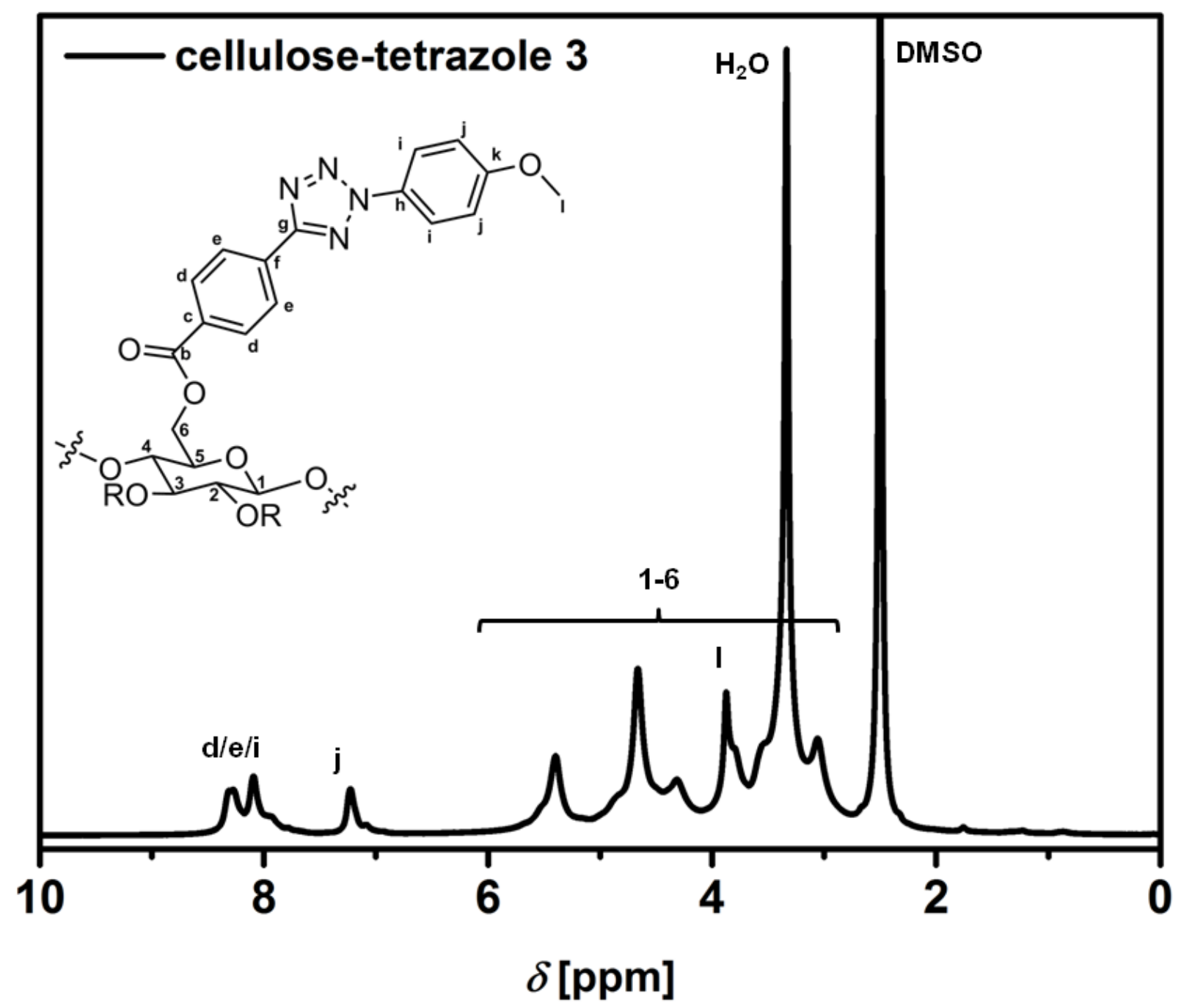

Figure S1: ${ }^{1} \mathrm{H}-\mathrm{NMR}$ spectrum of cellulose-tetrazole 3 in DMSO- $d_{6}$ as solvent. 


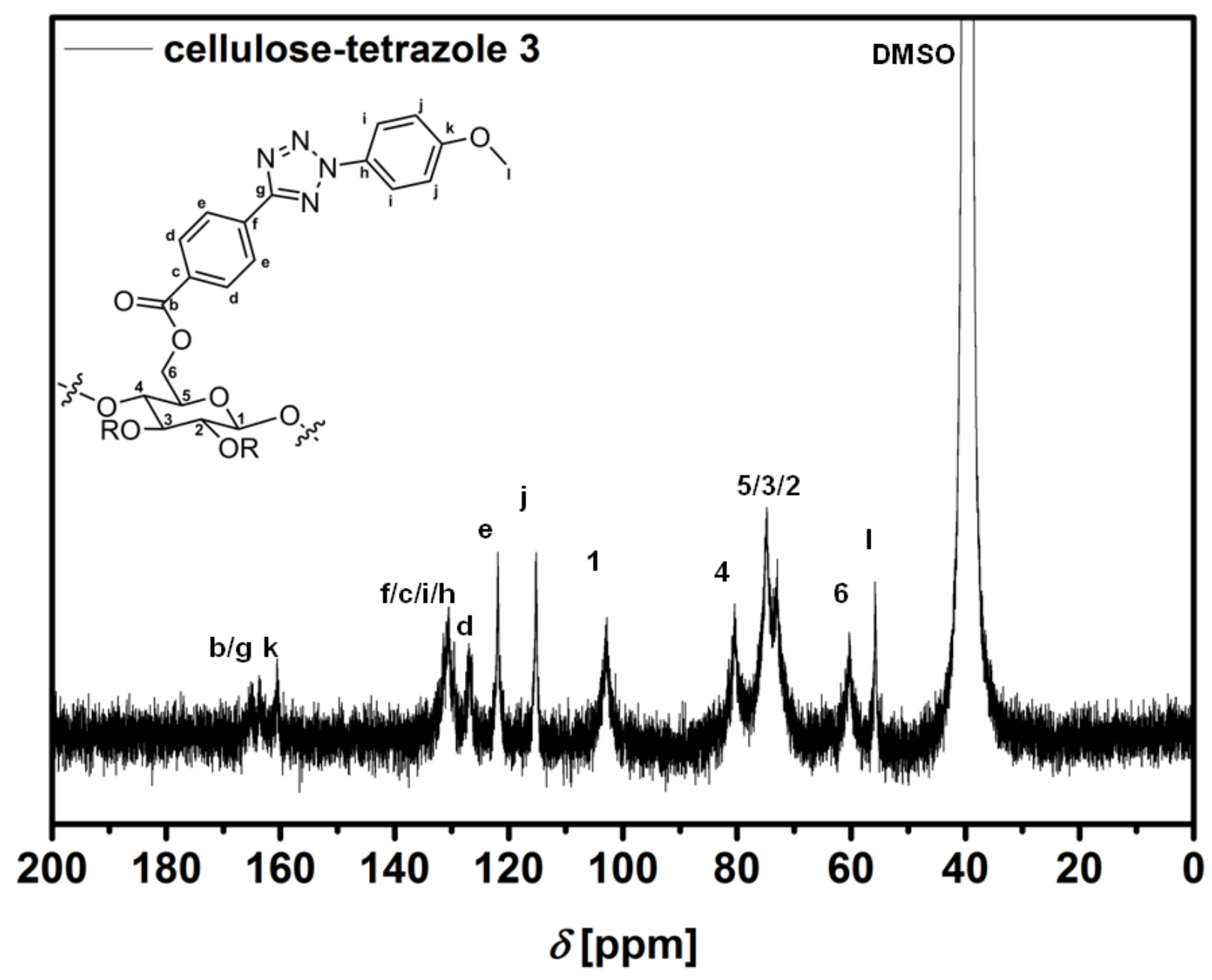

Figure S2: ${ }^{13} \mathrm{C}-\mathrm{NMR}$ spectrum of cellulose-tetrazole 3 in DMSO- $d_{6}$ as solvent. 


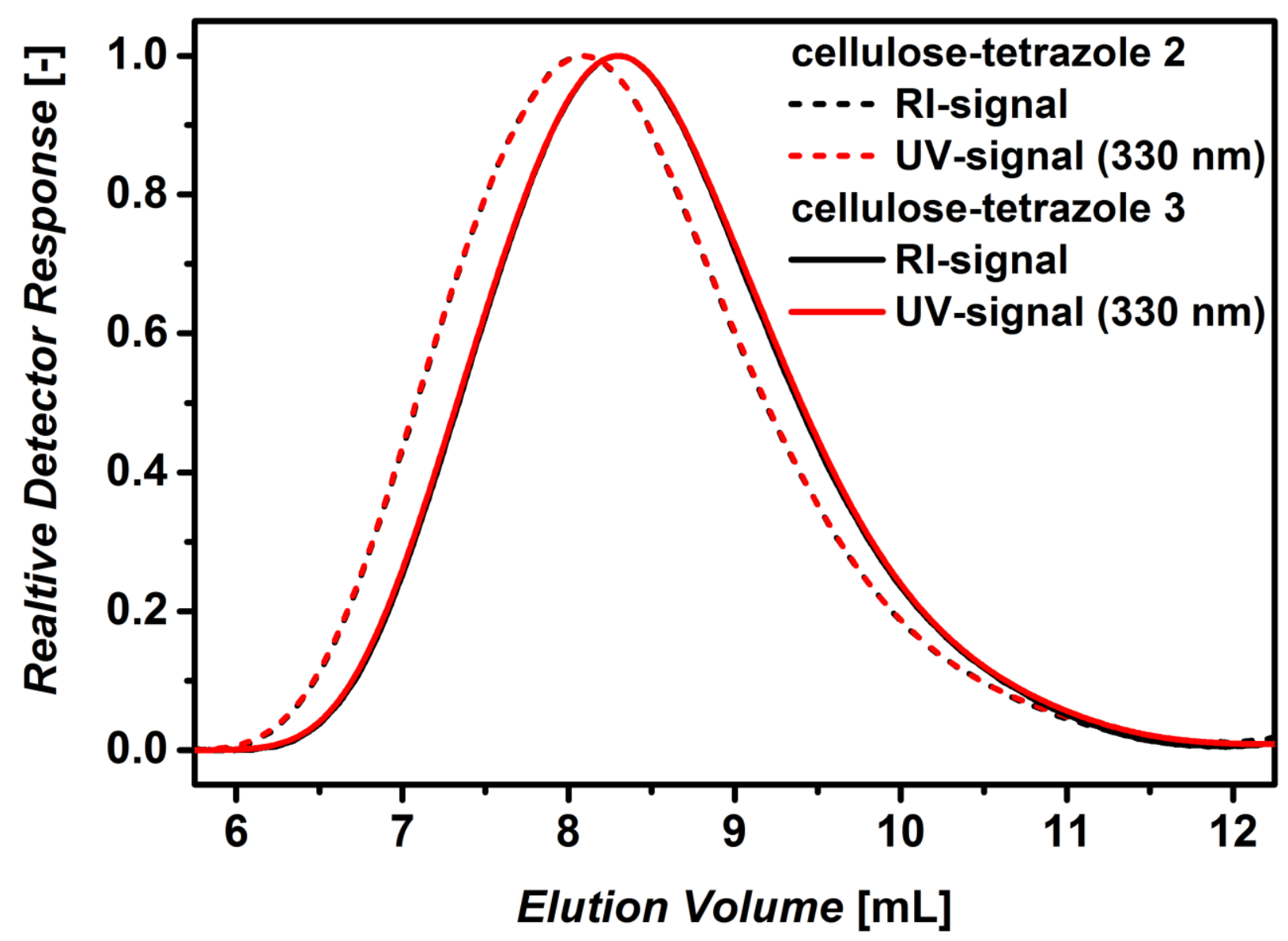

Figure S3: SEC traces of cellulose-tetrazole 2 (dashed line) and cellulose-tetrazole 3 (solid line) in $\mathrm{DMAc} / \mathrm{LiCl}$ as the eluent at $70{ }^{\circ} \mathrm{C} . M_{\mathrm{n}, \mathrm{SEC}, \mathrm{Uv}}\left(\right.$ cellulose-tetrazole 2) $=112000 \mathrm{~g} \mathrm{~mol}^{-1}$, $Ð=2.67 ; M_{\mathrm{n}, \mathrm{SEC}, \mathrm{Uv}}($ cellulose-tetrazole 3 $)=96000 \mathrm{~g} \mathrm{~mol}^{-1}, Ð=2.39$. 


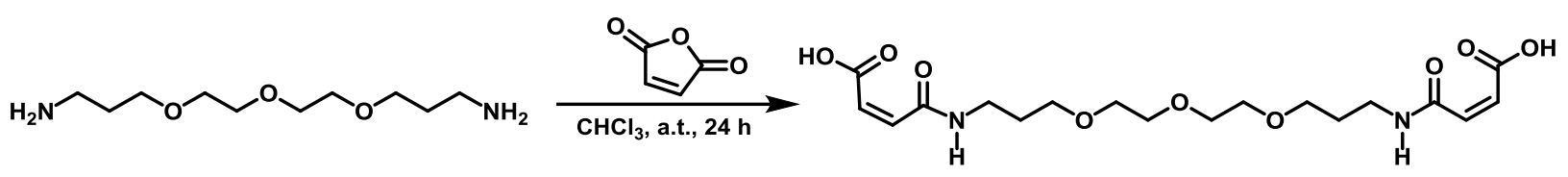

Scheme S2: Synthesis of $N, N^{\prime}$-[4,7,10-trioxa-tridecane]bismaleamic acid.

\section{$N, N^{\prime}-[4,7,10-$ Trioxa-tridecane]bismaleamic acid}

The synthesis was performed according to a previously reported procedure. ${ }^{7}$ A solution of maleic anhydride ( $8.90 \mathrm{~g}, 90.8 \mathrm{mmol}, 2.00$ equiv.) in chloroform $(50 \mathrm{~mL})$ was cooled to $0{ }^{\circ} \mathrm{C}$. After the dropwise addition of 4,7,10-trioxa-1,13-tridecanediamine (9.95 mL, 45.4 mmol 1.00 equiv.) dissolved in chloroform $(5 \mathrm{~mL})$ the reaction mixture was stirred at $0{ }^{\circ} \mathrm{C}$ for an additional $1 \mathrm{~h}$ and subsequently at ambient temperature overnight. The evaporation of the solvent gave $N, N^{\prime}-$ [4,7,10-trioxa-tridecane]bismaleamic acid as an intermediate product as a slightly yellow oil that was not further purified.

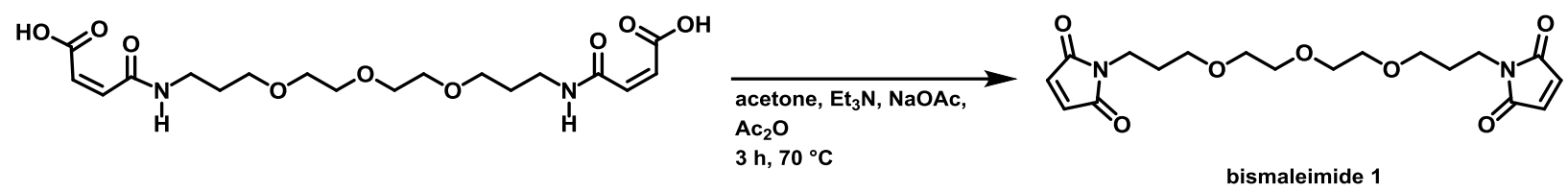

Scheme S3: Synthesis of $N, N^{\prime}$-[4,7,10-trioxa-tridecane]bismaleimide (bismaleimide 1).

\section{$N, N^{\prime}-[4,7,10-$ Trioxa-tridecane]bismaleimide (bismaleimide 1)}

The synthesis was performed according to a previously reported procedure. ${ }^{7}$ Triethylamine (4.12 mL, $29.5 \mathrm{mmol}, 0.65$ equiv.), sodium acetate $(2.83 \mathrm{~g}, 34.5 \mathrm{mmol}, 0.78$ equiv.) and acetic anhydride (27.25 mL, $288.3 \mathrm{mmol}, 6.35$ equiv.) were added to a solution of crude $N, N^{\prime}-[4,7,10$ trioxa-tridecane]bismaleamic acid (18.91 g, 45.4mmol, 1.00 equiv.) in acetone (80 mL). The 
reaction mixture was heated to reflux for $3 \mathrm{~h}$ and was allowed to cool slowly. After filtration, the solvent was removed under reduced pressure to give a brown oil. To remove the acetic acid/acetic anhydride mixture, the crude product was dissolved in water $(50 \mathrm{~mL})$ and stirred for additional $50 \mathrm{~h}$. The aqueous phase was extracted with dichloromethane $(3 \times 50 \mathrm{~mL})$. Purification by flash chromatography ( crystalline solid (yield: $52 \%) .{ }^{1} \mathrm{H}-\mathrm{NMR}\left(400 \mathrm{MHz}, \mathrm{DMSO}-d_{6}\right):[\delta, \mathrm{ppm}]=6.99(\mathrm{~s}, 4 \mathrm{H}$, $\mathrm{CH}=\mathrm{CH}), 3.49-3.41\left(\mathrm{~m}, 12 \mathrm{H}, 2 \times \mathrm{NCH}_{2}, 2 \times \mathrm{OCH}_{2} \mathrm{CH}_{2} \mathrm{O}\right), 3.37(\mathrm{t}, J=6.1,4 \mathrm{H}, 2 \times$ $\left.\mathrm{CH}_{2} \mathrm{CH}_{2} \mathrm{CH}_{2} \mathrm{O}\right), 1.81-1.62\left(\mathrm{~m}, 4 \mathrm{H}, 2 \times \mathrm{CH}_{2} \mathrm{CH}_{2} \mathrm{CH}_{2}\right)$.

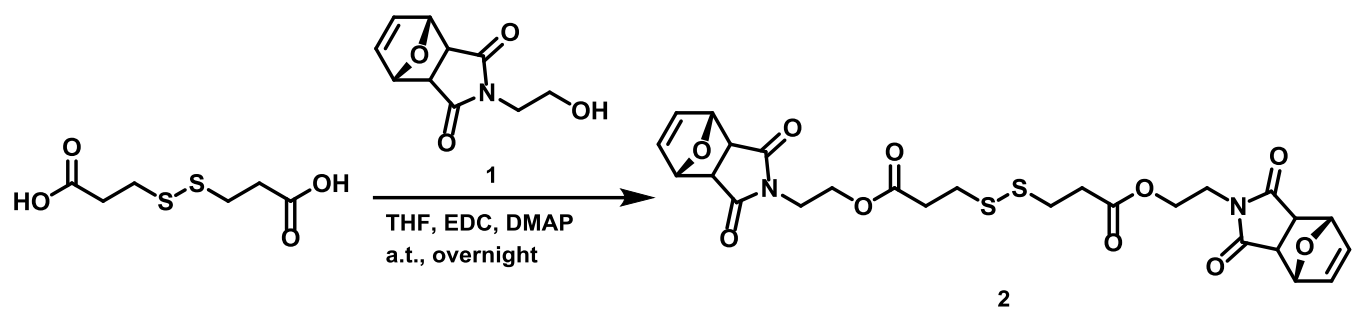

Scheme S4: Synthesis of 3,3'-dithiodipropionic acid di(2-(3,5-dioxo-10-oxa-4azatricyclo[5.2.1.0 $\left.0^{2,6}\right]$ dec-8-en-4-yl) ethyl ester) (2).

\section{3,3'-Dithiodipropionic acid di( 2-(3,5-dioxo-10-oxa-4-azatricyclo[5.2.1.0 $\left.{ }^{2,6}\right]$ dec-8-en-4-yl) ethyl ester) (2)}

4-(2-Hydroxyethyl)-10-oxa-4-azatricyclo[5.2.1.0 2,6]dec-8-ene-3,5-dione (1) was synthesized according to a procedure from the literature. ${ }^{8}$ To a solution of dithiodipropionic acid (1.00 g, $4.76 \mathrm{mmol}, 1.00$ equiv.) in $140 \mathrm{~mL}$ dry tetrahydrofuran (THF) alcohol 1 (2.98 g, $14.27 \mathrm{mmol}, 3$ equiv.) and DMAP (0.23 g, $1.90 \mathrm{mmol}, 0.40$ equiv.) were added at ambient temperature. The reaction mixture was cooled to $0{ }^{\circ} \mathrm{C}$, and $\operatorname{EDC}(2.74 \mathrm{~g}, 28.54 \mathrm{mmol}, 3.00$ equiv.) was added. After stirring for $1 \mathrm{~h}$ at $0{ }^{\circ} \mathrm{C}$ the reaction mixture was stirred at ambient temperature overnight. 
The solvent was removed under reduced pressure, and the residue was dissolved in $40 \mathrm{~mL}$ dichloromethane. The resulting solution was washed with saturated $\mathrm{NaHCO}_{3}$ solution $(100 \mathrm{~mL})$, brine $(3 \times 100 \mathrm{~mL})$, and water $(3 \times 100 \mathrm{~mL})$. The organic layer was dried over $\mathrm{MgSO}_{4}$. The solvent was removed under reduced pressure and the crude product was purified by column chromatography with cyclohexane/ethyl acetate (silica gel, 1/3 v/v) as the eluent. Product 2 was obtained as a white solid $(1.65 \mathrm{~g}, 60 \%) .{ }^{1} \mathrm{H}-\mathrm{NMR}\left(400 \mathrm{MHz}, \mathrm{DMSO}-d_{6}\right):[\delta, \mathrm{ppm}]=6.55(\mathrm{~s}, 4 \mathrm{H}$, $2 \times \mathrm{CH}=\mathrm{CH}), 5.13(\mathrm{~s}, 4 \mathrm{H}, 2 \times \mathrm{CHOCH}), 4.12\left(\mathrm{t}, J=5.5 \mathrm{~Hz}, 4 \mathrm{H}, 2 \times \mathrm{CH}_{2} \mathrm{O}\right), 3.62(\mathrm{t}, J=5.5 \mathrm{~Hz}$, $\left.4 \mathrm{H}, 2 \times \mathrm{CH}_{2} \mathrm{~N}\right), 2.94(\mathrm{~s}, 4 \mathrm{H}, 4 \times \mathrm{CHCON}), 2.85\left(\mathrm{t}, J=7.1 \mathrm{~Hz}, 4 \mathrm{H}, 2 \times \mathrm{CH}_{2} \mathrm{~S}\right), 2.61(\mathrm{t}, J=7.1$ $\left.\mathrm{Hz}, 4 \mathrm{H}, 2 \times \mathrm{CH}_{2} \mathrm{COO}\right)$.
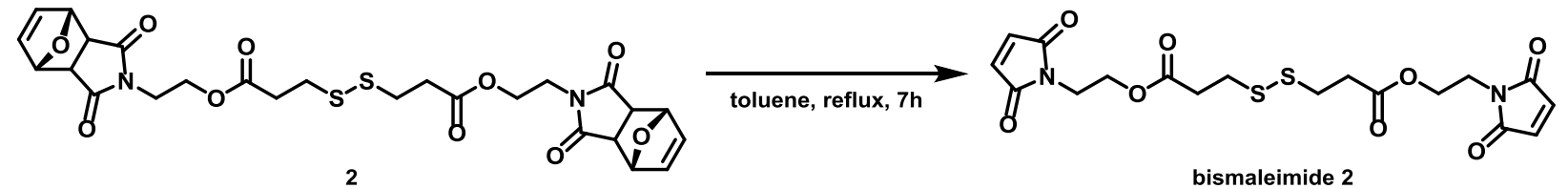

Scheme S5: Synthesis of 3,3'-dithiodipropionic acid di(2-(2,5-dioxo-2,5-dihydro-1H-pyrrol-1yl) ethyl ester) (bismaleimide 2).

\section{3,3'-Dithiodipropionic acid di(2-(2,5-dioxo-2,5-dihydro-1H-pyrrol-1-yl) ethyl ester) (bismaleimide 2)}

Product $2(0.60 \mathrm{~g}, 1.04 \mathrm{mmol})$ was treated according to a procedure from the literature. ${ }^{8}$ A pinch of hydroquinone was added to the reaction mixture. Bismaleimide $\mathbf{2}$ was obtained as an offwhite solid (0.44 g, 97\%). ${ }^{1} \mathrm{H}-\mathrm{NMR}\left(400 \mathrm{MHz}, \mathrm{DMSO}-d_{6}\right):[\delta, \mathrm{ppm}]=7.04(\mathrm{~s}, 4 \mathrm{H}, 2 \times$ $\mathrm{CH}=\mathrm{CH}), 4.16\left(\mathrm{t}, J=5.3 \mathrm{~Hz}, 4 \mathrm{H}, 2 \times \mathrm{CH}_{2} \mathrm{O}\right), 3.66\left(\mathrm{t}, J=5.3 \mathrm{~Hz}, 4 \mathrm{H}, 2 \times \mathrm{CH}_{2} \mathrm{~N}\right), 2.84(\mathrm{t}, J=6.9$ $\left.\mathrm{Hz}, 4 \mathrm{H}, 2 \times \mathrm{CH}_{2} \mathrm{~S}\right), 2.62\left(\mathrm{t}, J=6.9 \mathrm{~Hz}, 4 \mathrm{H}, 2 \times \mathrm{CH}_{2} \mathrm{COO}\right)$. 


\section{Exemplary procedure for network formation of cellulose-tetrazole with bismaleimide 1}

Cellulose-tetrazole 1 with $D S($ tetrazole $)=0.10(10.0 \mathrm{mg}, 0.053 \mathrm{mmol}$ AGU, $5.26 \mathrm{mmol}$ tetrazole, $1.00 \mathrm{eq})$ was dissolved in $150 \mu \mathrm{L} \mathrm{LiCl} / \mathrm{DMSO}\left(4 \mathrm{~g} \mathrm{~L}^{-1}\right)$ at $60{ }^{\circ} \mathrm{C} .25 \mu \mathrm{L}$ of a solution of bismaleimide 1 in $\mathrm{LiCl} / \mathrm{DMSO}\left(40.0 \mathrm{~g} \mathrm{~L}^{-1}, 1.0 \mathrm{mg}, 2.63 \mathrm{mmol}, 0.50\right.$ equiv./tetrazole) were added and the resulting solution was stirred for $1 \mathrm{~h}$ at $60^{\circ} \mathrm{C}$. The reaction was performed in a custom-built photoreactor equipped with a single compact low-pressure fluorescent lamp (36 W, Arimed B6, $\lambda_{\max }=320 \mathrm{~nm}$, Figure S4 and S5), and a magnetic stirrer and the samples were irradiated for pre-set time intervals at ambient conditions. In addition, a control sample containing no bismaleimide linker was irradiated for a given amount of time. Subsequently, $500 \mu \mathrm{L}(525 \mu \mathrm{L}$ for the control sample) of DMSO were added, the samples were placed in a shaker at $60^{\circ} \mathrm{C}$ and shaken at $400 \mathrm{~min}^{-1}$ for $4.5 \mathrm{~h} .25 \mu \mathrm{L}$ of the solution (that are not incorporated in the gel-like network) were diluted with $1 \mathrm{~mL}$ DMSO and subsequently analyzed by UV/vis spectroscopy. 
Table S1: Experimental conditions for the synthesis of cellulose networks with cellulosetetrazole 1 or cellulose-tetrazole 2 and bismaleimide 1. $c_{0}$ (cellulose-tetrazole) $\mathrm{UV}$ is the of concentration of cellulose-tetrazole at $t=0 \mathrm{~h}$ employed for the $\mathrm{UV} / \mathrm{vis}$ measurements.

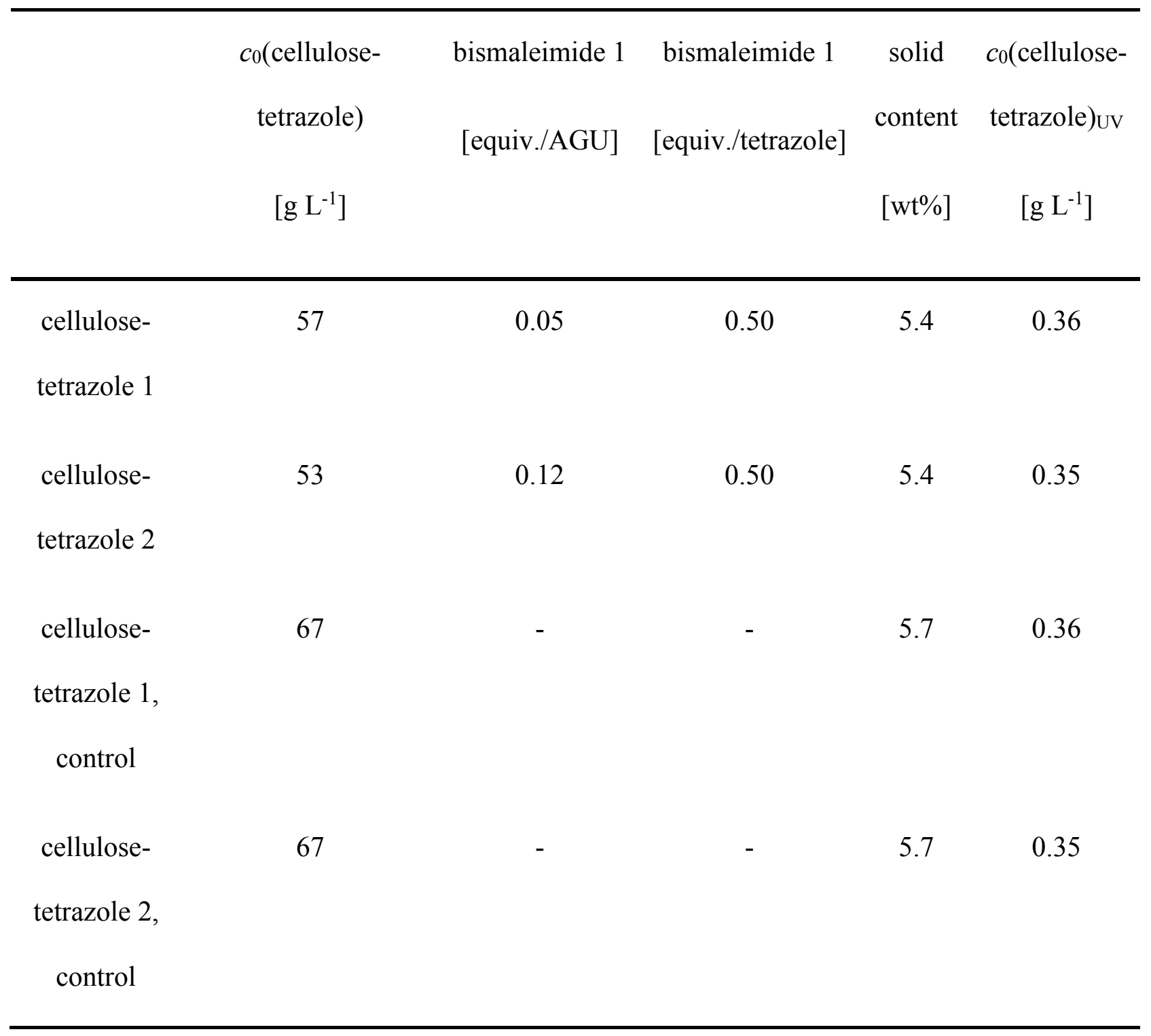




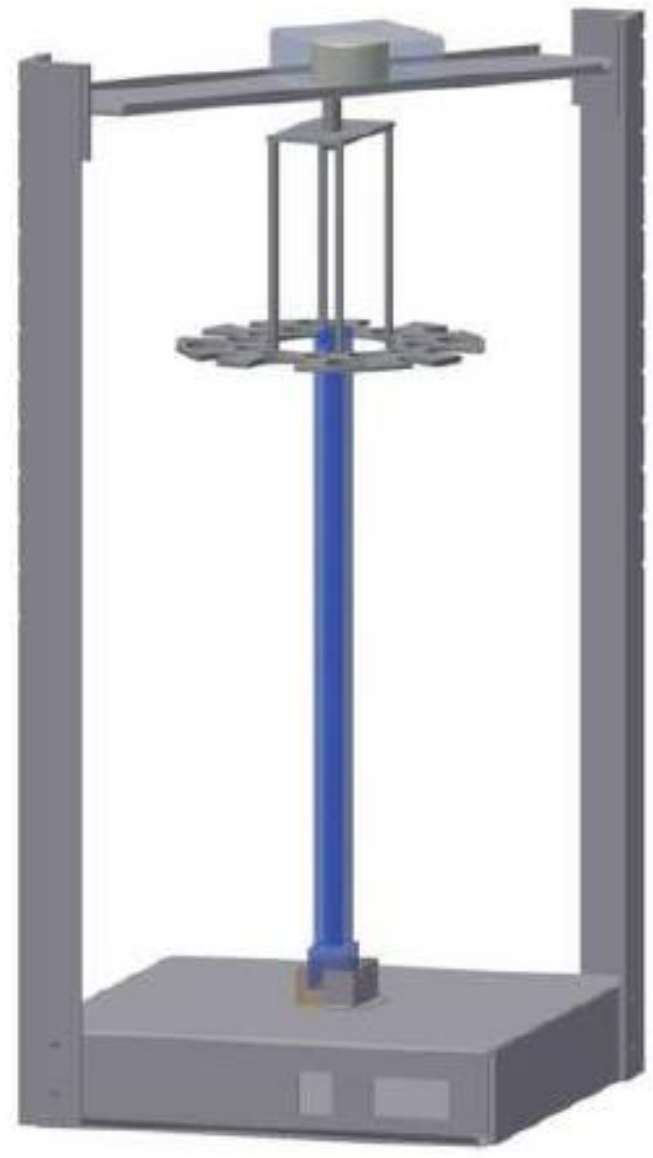

Figure S4: Illustration of the custom-built photoreactor used in the current work. 


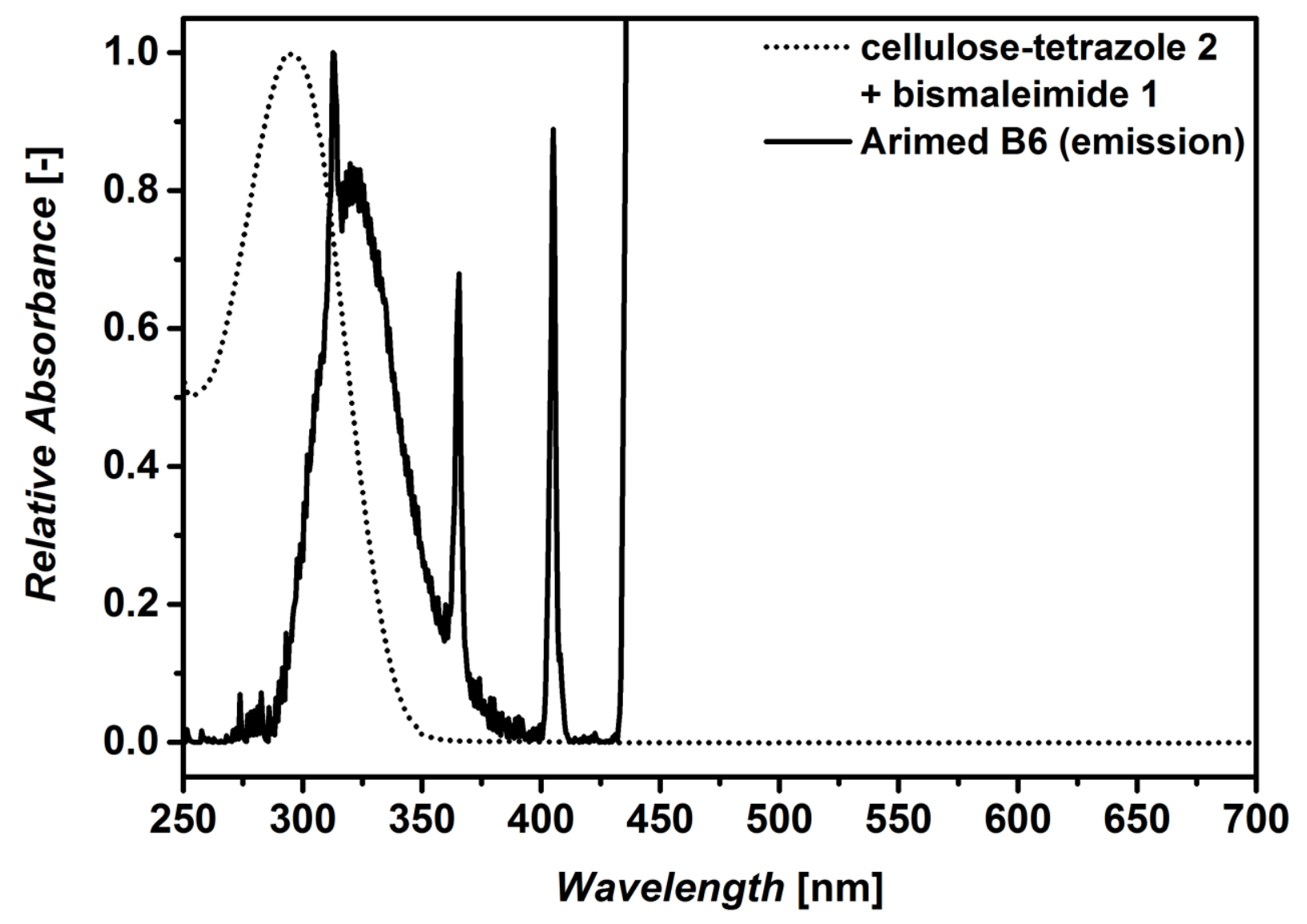

Figure S5: UV-vis absorption spectrum of cellulose-tetrazole 2 and bismaleimide 1 in DMSO and emission spectrum of the Arimed B6 lamp used in the current study. The absorbance and the emission are given relative to the peak maximum at $300 \mathrm{~nm}$ or $320 \mathrm{~nm}$, respectively. The emission spectrum of the Arimed B6 lamp was measured on a spectroradiometer UVpad E, Opsytec Dr. Gröbel, Ettlingen, Germany, operating in the range of wavelenths from 200 $440 \mathrm{~nm}$. The power density was determined as $6.72 \mathrm{~mW} \mathrm{~cm}^{-2}$ at a $5 \mathrm{~cm}$ distance used in the crosslinking of cellulose films. 
a)

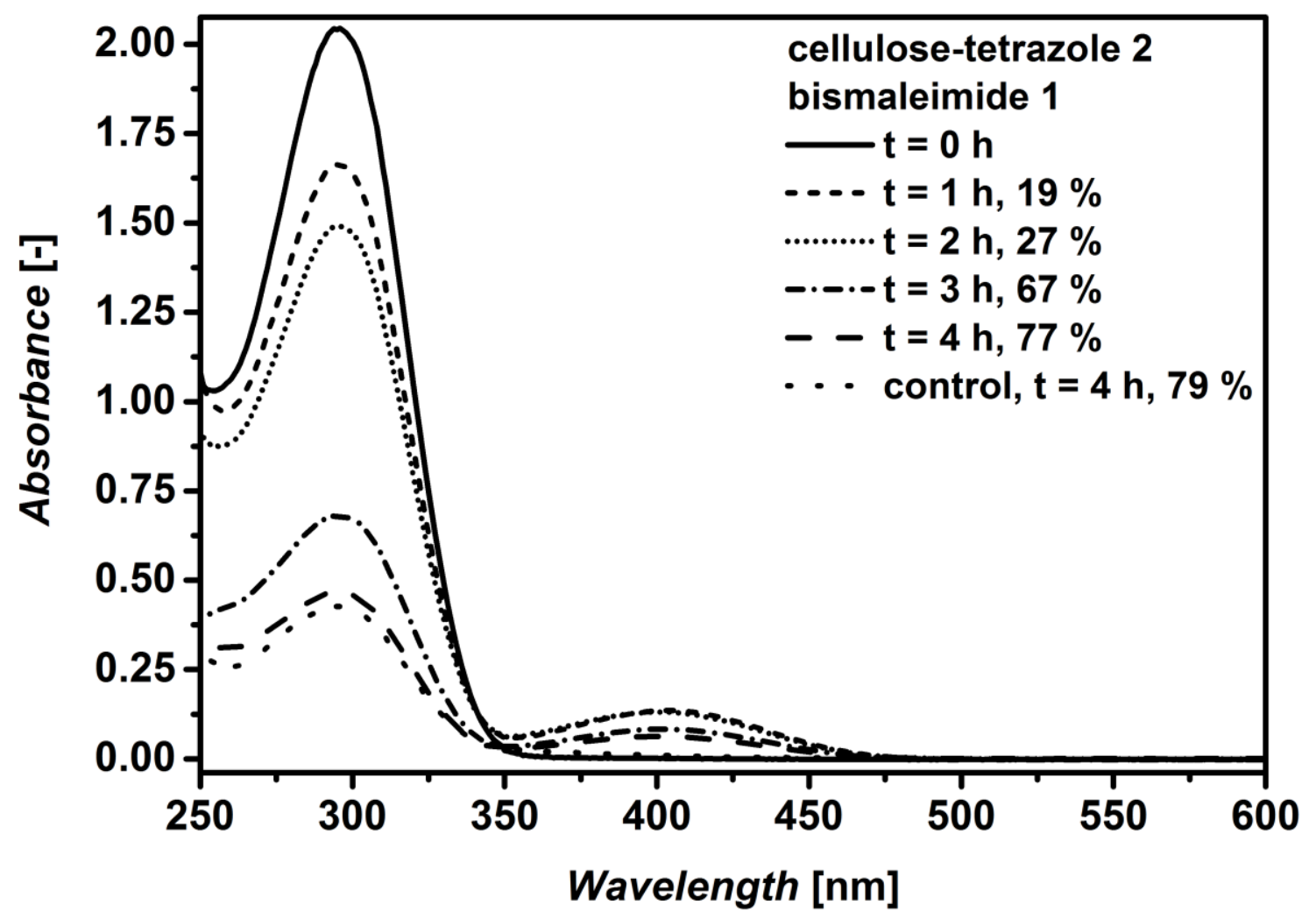

b)

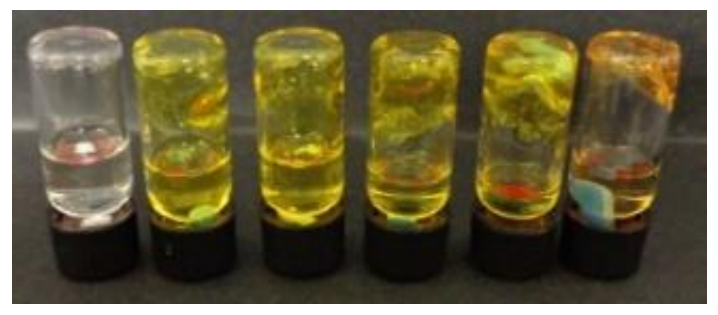

c)

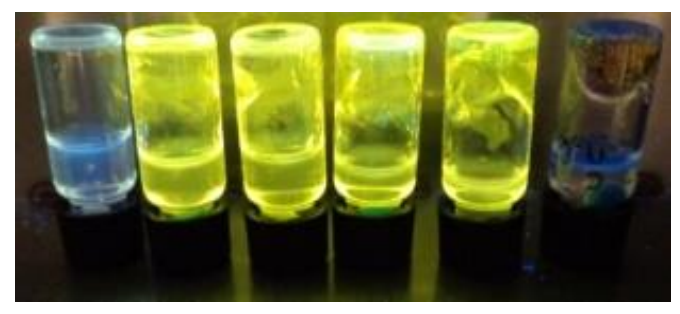

Figure S6: a) UV/vis investigation of the incorporation of cellulose-tetrazole 2 in networks employing bismaleimide 1 as crosslinker with increasing irradiation time. The decrease in tetrazole absorbance is given in percent with respect to the peak maximum. b) Cellulose network samples corresponding to Figure S6 a after swelling in DMSO for $4 \mathrm{~h}$ at daylight (left: $\mathrm{t}=0 \mathrm{~h}$; middle:from left to right; $t=1-4 h$; right: control, $t=4 h$ ). c) Cellulose network samples from Figure S6 b under irradiation with light at $365 \mathrm{~nm}$. 


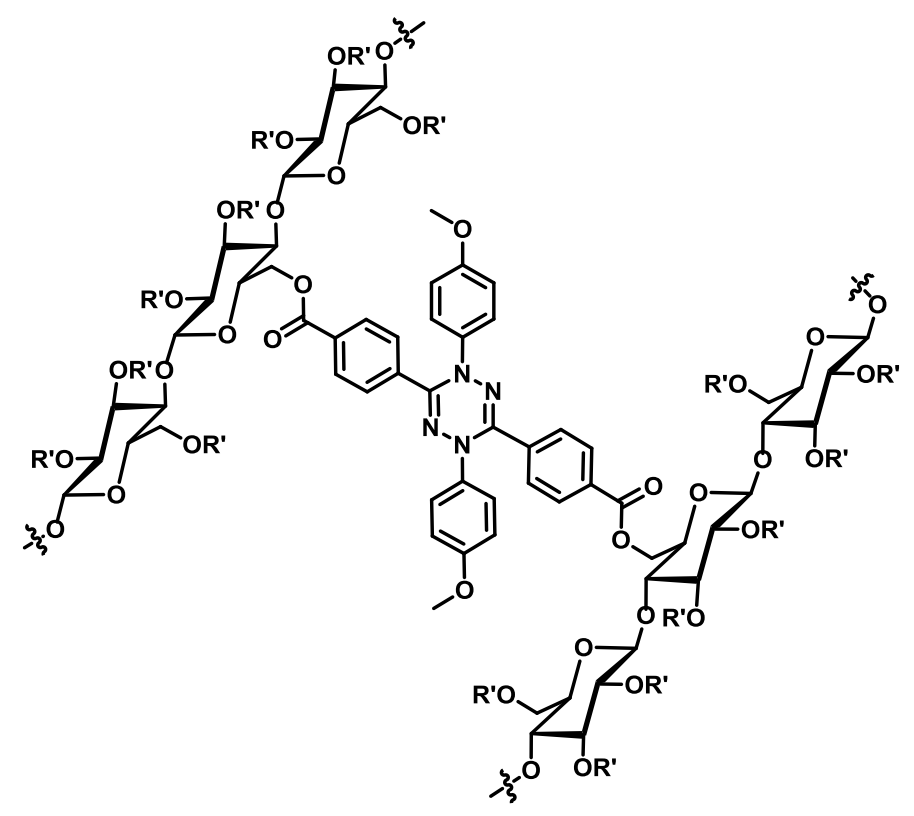

Chart S1: 1.4-Dihydro-1.2.4.5-tetrazines forming in the absence of suitable dipolarophiles. ${ }^{9}$ 


\section{Exemplary procedure for preparation of films of cellulose-tetrazole with bismaleimide}

linkers. Cellulose-tetrazole $3(80.0 \mathrm{mg}, 398 \mathrm{mmol}$ AGU, $55.7 \mathrm{mmol}$ tetrazole, 1 equiv.) was dissolved in $575.2 \mu \mathrm{L} \mathrm{LiCl/DMSO}\left(4 \mathrm{~g} \mathrm{~L}^{-1}\right)$ at $60^{\circ} \mathrm{C}$ overnight. $74.8 \mu \mathrm{L}$ of a solution of bismaleimide 1 in $\mathrm{LiCl} / \mathrm{DMSO}\left(142 \mathrm{~g} \mathrm{~L}^{-1}, 27.8 \mathrm{mmol}, 0.50\right.$ equiv./tetrazole) or solid bismaleimide 2 (12.7 mg, $27.8 \mathrm{mmol}, 0.50$ equiv./tetrazole) and $74.8 \mu \mathrm{L} \mathrm{LiCl} / \mathrm{DMSO}$ was added and the resulting solution was stirred at $60{ }^{\circ} \mathrm{C}$ for $1 \mathrm{~h}$. The solution was drop cast onto a glass slide and spread into a film with a thickness of $120 \mu \mathrm{L}$ employing a scraper. A few drops of methanol were placed on the films to induce physical crosslinking. For the spatial resolution experiments, a glass slide with a shadow mask with a hole of approx. $5 \mathrm{~mm}$ diameter, consisting of a piece of aluminum foil that was treated with a standard hole puncher, was placed on top of the film. The films were crosslinked in a custom-built photoreactor equipped with a single compact low-pressure fluorescent lamp (36 W, Arimed B6, $\lambda_{\max }=320 \mathrm{~nm}$, Figure S4 and S5) in a $90^{\circ}$ angle for $12 \mathrm{~h}$. The samples were removed from the glass slides and shaken in DMSO at $60{ }^{\circ} \mathrm{C}$ and $400 \mathrm{~min}^{-1}$ for $6 \mathrm{~h}$. Subsequently, the samples were removed from DMSO, rinsed with DMSO and subsequently with ethanol, immersed in ethanol overnight, rinsed with ethanol again and dried at $50^{\circ} \mathrm{C}$ under vacuum for $8 \mathrm{~h}$. 
Table S2: Experimental conditions for the formation of cellulose thin films using cellulosetetrazol 2 or cellulose-tetrazole 3 and bismaleimide 1 or bismaleimide 2 .

\begin{tabular}{|c|c|c|c|c|c|}
\hline & $\begin{array}{l}c(\text { cellulose- } \\
\text { tetrazole-2) }\end{array}$ & $\begin{array}{l}c(\text { cellulose- } \\
\text { tetrazole-3) }\end{array}$ & $\begin{array}{l}\text { bismaleimide } 1 \\
\text { [equiv./tetrazole] }\end{array}$ & $\begin{array}{l}\text { bismaleimide } 2 \\
\text { [equiv./tetrazole] }\end{array}$ & $\begin{array}{l}\text { solid } \\
\text { content }\end{array}$ \\
\hline & {$\left[\mathrm{g} \mathrm{L}^{-1}\right]$} & {$\left[\mathrm{g} \mathrm{L}^{-1}\right]$} & & & {$[\mathrm{wt} \%]$} \\
\hline network 1 & 123 & - & 0.50 & - & 12 \\
\hline network 2 & 123 & - & - & 0.50 & 12 \\
\hline network 3 & - & 123 & 0.50 & - & 11 \\
\hline network 4 & - & 123 & - & 0.50 & 11 \\
\hline
\end{tabular}




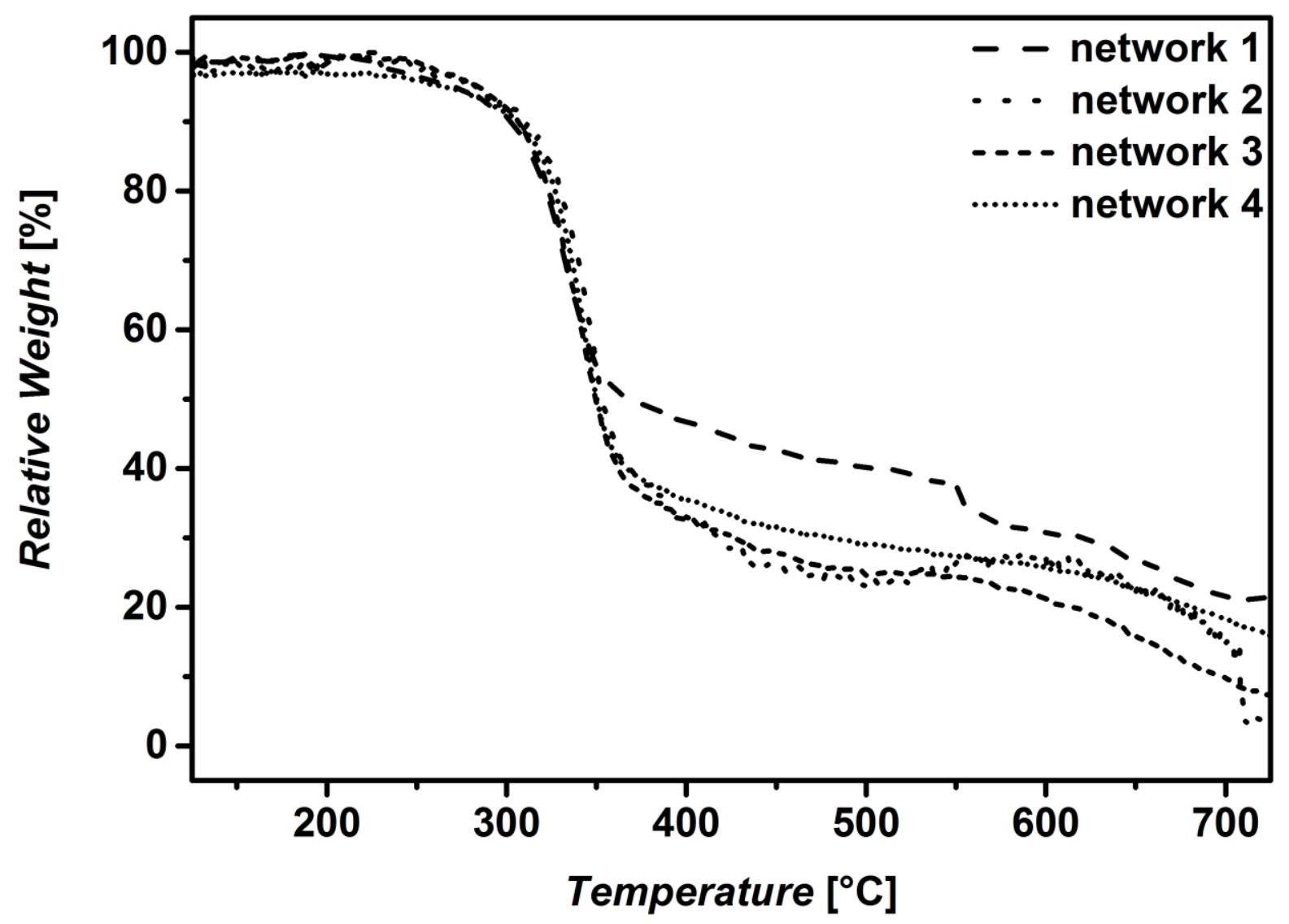

Figure S7: TGA data on networks 1-4 obtained at a heating rate of $10 \mathrm{~K} \mathrm{~min}^{-1}$. 

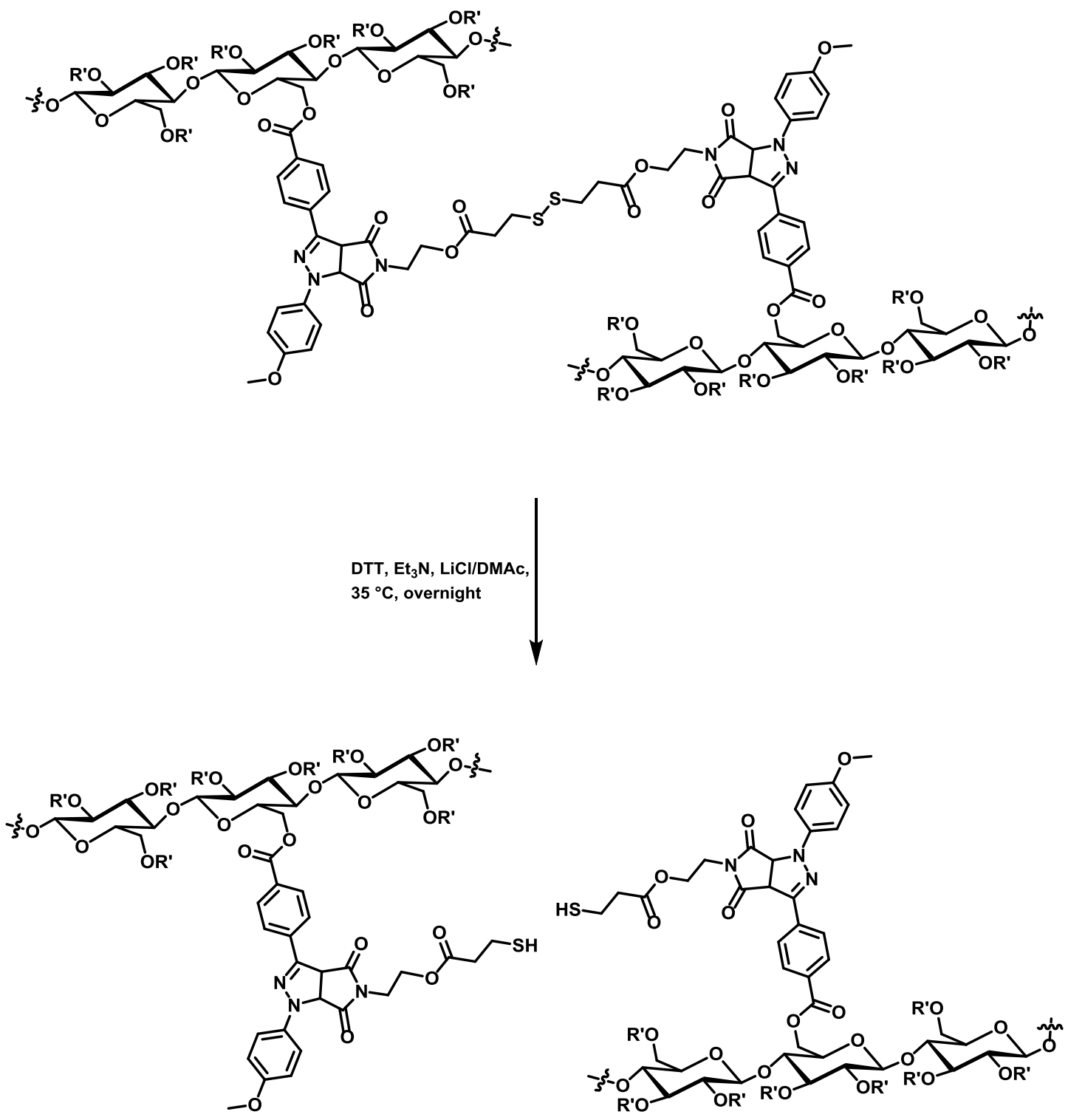

Scheme S6: Reduction of disulfide bonds of network 2 and network 4 resulting in the cleavage of crosslinks.

\section{Exemplary procedure for reduction of cellulose-tetrazole bismaleimide networks}

Network $4(1.65 \mathrm{mg})$ was swollen in $1 \mathrm{~mL}$ DMSO at $60{ }^{\circ} \mathrm{C}$ in a shaker at $200 \mathrm{~min}^{-1}$ overnight. Subsequently, the DMSO was decanted and $16.5 \mathrm{mg}$ DTT, $14.9 \mu \mathrm{L}$ triethylamine, and $1.6 \mathrm{~mL}$ $\mathrm{LiCl} / \mathrm{DMAc}\left(10 \mathrm{~g} \mathrm{~L}^{-1}\right.$ for SEC) were added. The sample was degassed with argon for $10 \mathrm{~min}$ and 
placed in a shaker at $35^{\circ} \mathrm{C}$ and $200 \mathrm{~min}^{-1}$ overnight. Finally, the solution was filtered through a syringe filter and subjected to SEC analysis.

a)

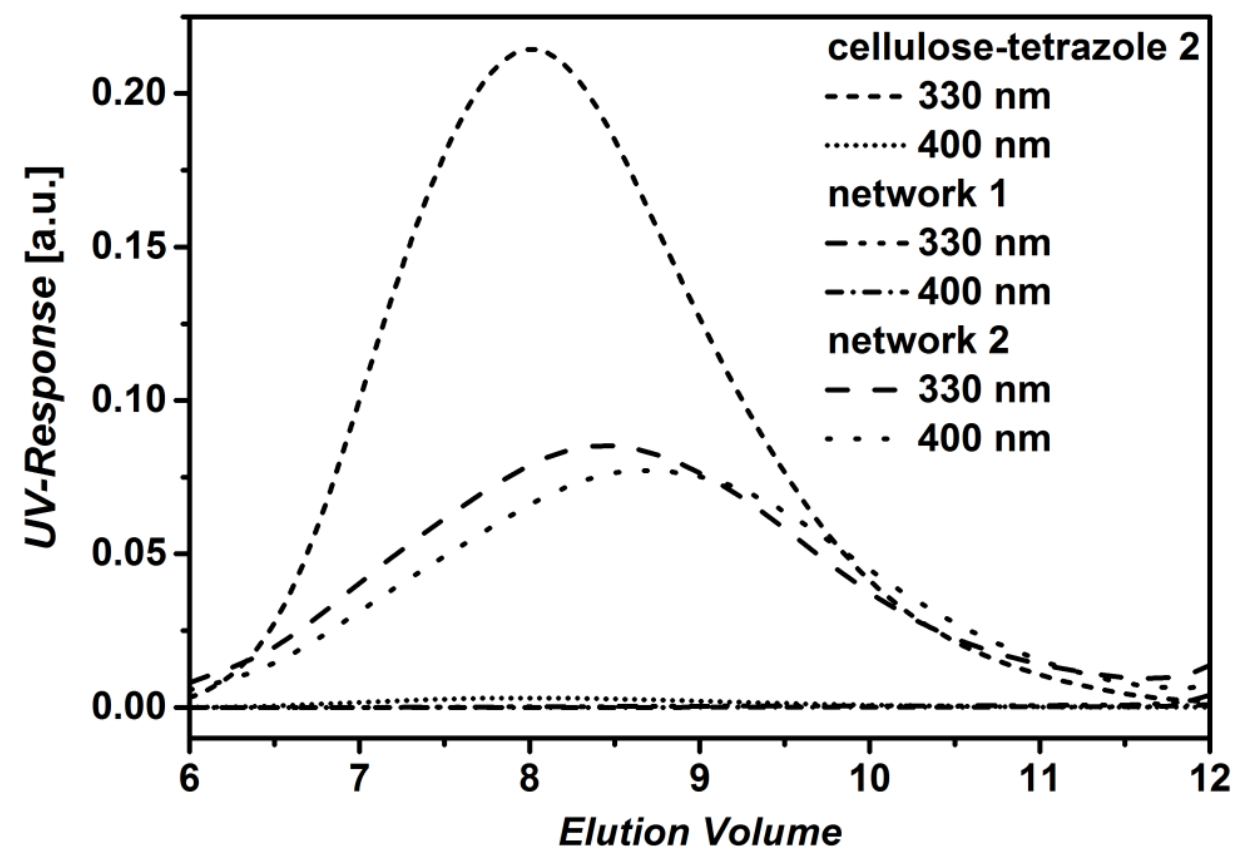

b)
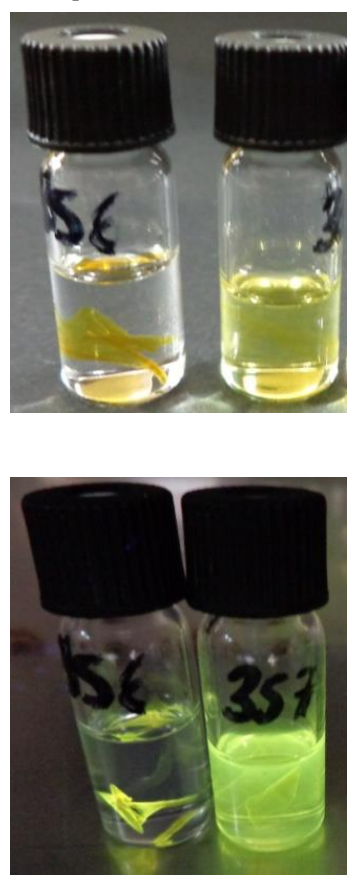

Figure S8: a) SEC traces of cellulose-tetrazole 2 and network 1 and network 2 after treatment with DTT measured with a UV detector at $330 \mathrm{~nm}$ and $400 \mathrm{~nm}$. b) network 1 (left) and network 2 (right) in DMAc/LiCl after treatment with DTT at daylight (top) and under irradiation at $365 \mathrm{~nm}$ (bottom). 


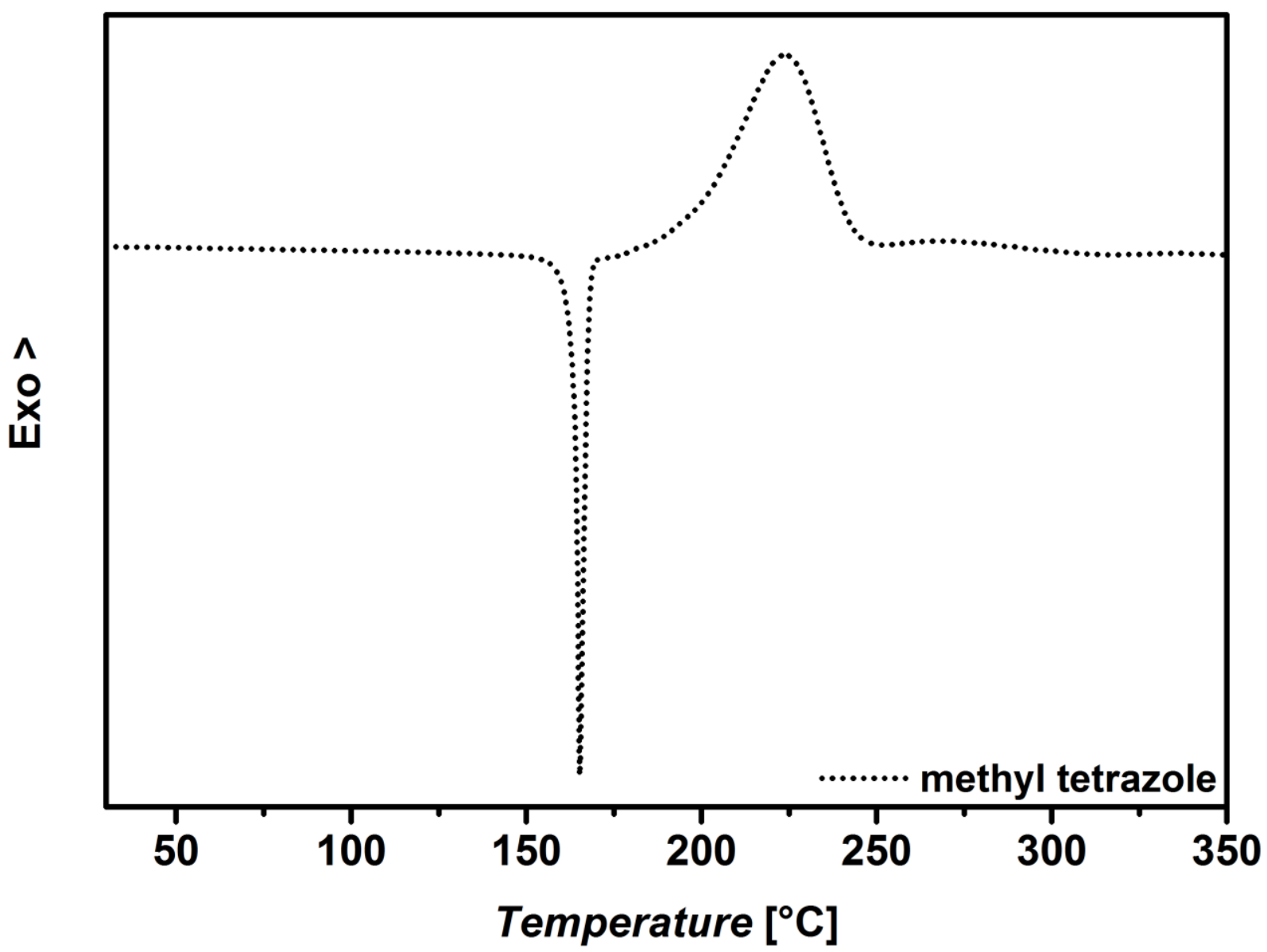

Figure S9: DSC trace of methyl tetrazole.

\section{References}

1. Huijbrechts, A. A. M. L.; Huang, J.; Schols, H. A.; van Lagen, B.; Visser, G. M.; Boeriu, C. G.; Sudhölter, E. J. R. J. Polym. Sci., Part A: Polym. Chem. 2007, 45, 2734-2744.

2. Mantovani, G.; Lecolley, F.; Tao, L.; Haddleton, D. M.; Clerx, J.; Cornelissen, J. J. L. M.; Velonia, K. J. Am. Chem. Soc. 2005, 127, 2966-2973.

3. Hufendiek, A.; Trouillet, V.; Meier, M. A. R.; Barner-Kowollik, C. Biomacromolecules 2014, 15, 2563-2572.

4. Strlič, M.; Kolenc, J.; Kolar, J.; Pihlar, B. J. Chromatogr. A 2002, 964, 47-54.

5. Sjöholm, E.; Gustafsson, K.; Eriksson, B.; Brown, W.; Colmsjö, A. Carbohydr. Polym. 2000, 41, 153-161.

6. Schenzel, A.; Hufendiek, A.; Barner-Kowollik, C.; Meier, M. A. R. Green Chem. 2014, 16, 3266-3271.

7. $\quad$ Bays, E.; Tao, L.; Chang, C.-W.; Maynard, H. D. Biomacromolecules 2009, 10, 17771781. 
8. Rodriguez-Emmenegger, C.; Preuss, C. M.; Yameen, B.; Pop-Georgievski, O.; Bachmann, M.; Mueller, J. O.; Bruns, M.; Goldmann, A. S.; Bastmeyer, M.; Barner-Kowollik, C. Adv. Mater. 2013, 25, 6123-6127.

9. Ji, Y.; Sweeney, J.; Zoglio, J.; Gorin, D. J. J. Org. Chem. 2013, 78, 11606-11611. 